\title{
REVIEW
}

\section{Liver transplantation for chronic liver disease: advances and controversies in an era of organ shortages}

\author{
M I Prince, M Hudson
}

Postgrad Med J 2002;78:135-141

Since liver transplantation was first performed in 1968 by Starzl et al, advances in case selection, liver surgery, anaesthetics, and immunotherapy have significantly increased the indications for and success of this operation. Liver transplantation is now a standard therapy for many end stage liver disorders as well as acute liver failure. However, while demand for cadaveric organ grafts has increased, in recent years the supply of organs has fallen. This review addresses current controversies resulting from this mismatch. In particular, methods for increasing graft availability and difficulties arising from transplantation in the context of alcohol related cirrhosis, primary liver tumours, and hepatitis $C$ are reviewed. Together these three indications accounted for $42 \%$ of liver transplants performed for chronic liver disease in the UK in 2000. Ethical frameworks for making decisions on patients' suitability for liver transplantation have been developed in both the USA and the UK and these are also reviewed.

See end of article for authors' affiliations

.................

Correspondence to: Dr Martin I Prince, School of Clinical Medical Sciences, Floor 4, William Leech Building, Newcastle Medical School, Newcastle upon Tyne NE2 4HH, UK;

Martin.prince@doctors.net.uk

Submitted 20 June 2001

Accepted

19 October 2001
$\mathrm{T}$ homas Starzl et al first reported successful human orthotopic liver transplantation in 1968 in Pittsburgh, USA. ${ }^{1}$ Since then liver transplantation has become one of the standard therapeutic options for advanced chronic liver disease and selected patients with acute liver failure (most commonly due to paracetamol overdose or viral infection). In the year 2000, 678 liver transplants were performed for chronic liver disease in the UK. The indications for these transplants are shown in fig 1 .

Improvements in surgical techniques and immunosuppression have markedly increased the success rates of liver transplantation. Much of the morbidity and mortality associated with transplantation is concentrated in the first postoperative month when the risks of rejection, sepsis, and surgical complications are highest, particularly after acute liver failure. However, after this the outlook for most patients is excellent. As shown in fig 2, one and five year patient survival after transplant is $81 \%$ and $66 \%$ respectively. Furthermore many patients can return to a normal level of social and physical functioning with a vastly improved quality of life. ${ }^{2}$

The success of liver transplantation has lead to increasing numbers of referrals. However, at the same time the availability of cadaveric organs has diminished (partially due to improvements in road safety), resulting in the number of potential recipients for liver transplantation exceeding organ supply with attendant deaths of patients on waiting lists. We review areas of controversy and new approaches developing in response to this mismatch.

\section{IMPROVING THE RATIO OF TRANSPLANT SUPPLY AND DEMAND}

There are three approaches to improving the ratio of liver availability to potential recipients. First, to maximise efficiency of liver distribution between centres; second, to examine ways of expanding the donor pool; and third, to impose limits on use of livers for certain indications. Xenotransplantation is not currently an option for human liver transplantation.

Organ distribution protocols minimise inequalities in supply and demand between regions and therefore improve the efficiency of organ utilisation. This is most important for patients with acute liver failure where the "window" between listing for transplant and death may only be one to three days. In such cases patients in the UK are assigned to a "super-urgent" list and receive the first suitable liver available from any centre in the UK.

Four methods to increase the donor pool of livers for transplantation have been proposed. First, legislative changes may increase the numbers of patients donating organs. Changing the current system, which requires the potential donors to register approval of the use of their organs before death (an "opt in" system) to one where patients are assumed not to object to donation unless otherwise noted (an "opt out" system) has received considerable media coverage. At present the legislative and ethical barriers to this have not been overcome in the UK.

The second method for increasing organ availability has been to use "marginal" livers that would previously have been regarded as unsuitable for transplantation. Three categories of "marginal" livers have been considered. Livers from donors who have suffered brief cardiopulmonary arrest have not generally been used for transplantation because of the potential for damage to the grafted liver. However, Totsuka et al recently reported that despite early biochemical abnormalities, 90 day graft survival was similar to that from conventional donors, suggesting that these should be more widely used. ${ }^{3}$ Similarly, livers showing macroscopic evidence of steatosis (fatty liver) were previously thought unsuitable for transplantation because of an increased risk of primary graft non-function. However, this increased risk is mainly restricted to livers with 


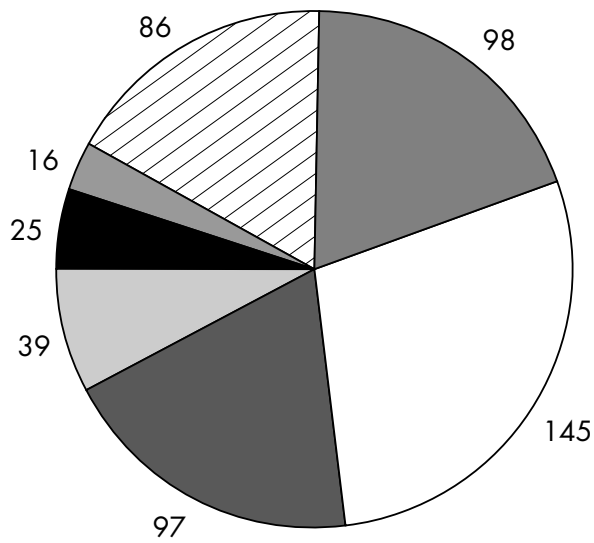

Alcoholic cirrhosis

$\square$ Autoimmune liver disease (including PBC, $\mathrm{AlH}$, and PSC)

Hepatitis $C$

Cryptogenic cirrhosis

Hepatitis B

Hepatocellular carcinoma

Other

Figure 1 Indications for primary liver transplantation in the UK in 2000; AlH, autoimmune hepatitis, PBC, primary biliary cirrhosis; PSC, primary sclerosing cholangitis. (Statistics prepared by UK Transplant from the National Transplant Database maintained on behalf of transplant services in the UK and Republic of Ireland.)

severe steatosis (microscopic steatosis in over 60\% of hepatocytes $).{ }^{4}$ Increasingly transplant centres are using livers with mild (less than $30 \%$ ) or moderate $(30 \%-60 \%)$ steatosis, although there is still a small increased risk of primary non-function with moderate steatosis. Finally, livers from hepatitis $\mathrm{C}$ positive donors may be transplanted into hepatitis $\mathrm{C}$ positive recipients. As discussed below, graft reinfection is universal in patients who are hepatitis C RNA positive pre-transplant. Hence, provided that the donor liver is not significantly fibrotic before transplantation, postoperative survival may be unimpaired. Recent reports from the USA suggest survival is at least equal to that of conventional donors. ${ }^{56}$ Hepatitis $\mathrm{C}$ positive donors are not currently used in Europe.

The third method for improving liver supply has been to share a single organ between two recipients by surgically splitting the donor liver. This approach originated in paediatric liver transplant programmes where extreme shortages of child donors led to use of surgically reduced adult livers (primarily the left lateral lobe). ${ }^{7}$ The remaining segment (an extended right lobe) of liver could then be used in an adult recipient. This graft regenerates over three to six months to close to normal adult size. Subsequent work has defined the optimal method for organ splitting together with estimates of the minimum ratio of organ section size to recipient weight allowing organ sharing between two adults. Current practice in the USA favours in situ (that is before removal from the native donor blood supply) splitting of the donor liver along the anatomical boundary between left and right lobes. ${ }^{8}$ The transplanted liver section must be at least $50 \%$ of the recipient's standard liver volume (a measure of the expected healthy liver volume based on recipient's height and weight) to provide adequate function for patient survival before liver regeneration. ${ }^{9}$ Although the success rates of these methods are improving, the adult recipient still has survival below that expected with whole organ transplantation ${ }^{8}$ and accordingly

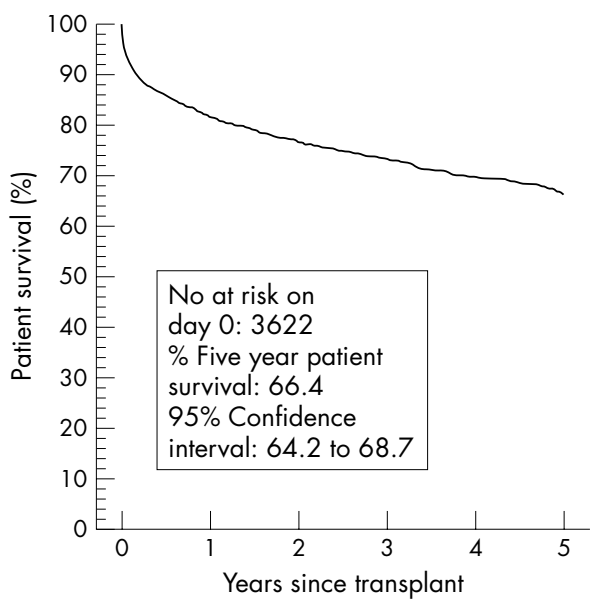

Figure 2 Kaplan-Meier estimates of five year patient survival after non-urgent liver transplants in the UK, 1 January 1994 to 31 December 2000. (Statistics prepared by UK Transplant from the National Transplant Database maintained on behalf of transplant services in the UK and Republic of Ireland.)

these methods are not in widespread use in the UK. Furthermore few British centres have the facilities to perform two transplant operations simultaneously. However, these techniques are gaining favour in the USA where waiting lists are longer and the excess mortality due to decreased operative success rates may be outweighed by reduced mortality on the waiting list.

The final method for increasing organ availability has been to transplant segments of livers from living donors. These methods were primarily derived in Japan where legislation previously precluded cadaveric donation and over 400 such operations have been performed to date. ${ }^{10}$ The surgical methods adopted are similar to liver splitting, although the right lobe is now favoured for transplantation. ${ }^{11}$ As the graft comes from a healthy donor, a slightly reduced volume ratio (40\%) is acceptable. ${ }^{12}$ There are ethical problems with this approach however. ${ }^{13}$ Deaths among living related donors have recently been recorded along with a substantial morbidity rate (estimated at $4 \%) .{ }^{11}$ Furthermore, issues regarding donor consent and the exclusion of coercion by the recipient (whether intentional or not) are unclear. Perhaps the greatest potential for these techniques would be in the treatment of acute liver failure, ${ }^{9}$ however the potential for unintentional coercion here is highest given the short period available to obtain consent. ${ }^{14}$ Given these unresolved problems, living related liver segment donation is used only occasionally in the UK, mainly in paediatric patients.

The final method for matching organ availability and requirements is to limit the indications for transplantation and thus reduce demand. Ideally transplantation would be limited to those patients with the highest predicted mortality with conservative therapy and the highest long term survival after transplant. Three indications for transplantation, alcoholic liver disease (ALD), recurrent hepatitis C, and hepatocellular carcinoma, have been questioned from this perspective.

\section{LIVER TRANSPLANTATION FOR ALCOHOLIC LIVER DISEASE}

ALD is the commonest cause of chronic liver failure in Europe and North America and is one of the most controversial indications for transplantation. A survey of attitudes to liver transplantation reported that ALD is the least popular reason for transplantation both among the public and family physicians. ${ }^{15}$ However, the sheer burden of alcoholic cirrhosis means that ALD accounts for a substantial and increasing proportion of all liver transplantation (fig 3). 


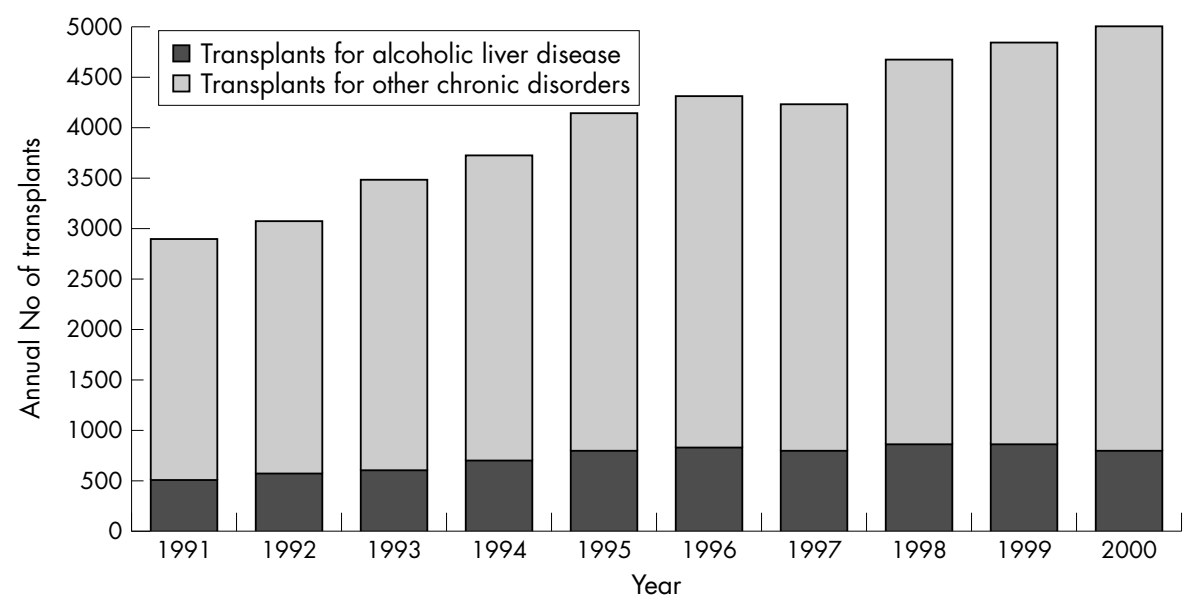

Figure 3 Proportion of liver transplants due to alcoholic liver disease in the USA, 1990 to 2000 (Adapted from data in Belle et al ${ }^{16}$ and Neuberger and Tang ${ }^{17}$.)
The concerns about offering transplantation for ALD stem from reluctance to "waste" a liver on a "self induced" disease and the potential for recurrent alcoholic abuse after transplantation. From a clinical perspective ALD is a very good indication for transplantation with a similar or better prognosis after transplantation to most other liver diseases except cholestatic liver disease. ${ }^{16}$

Two questions underlie much of the controversy regarding transplantation for ALD. How can one predict who is likely to relapse after transplantation and how can we prevent relapse in these patients?

Studies of recidivism after transplantation are difficult to compare because of differences both in definitions of recidivism (ranging from any alcohol use to continuous heavy alcohol usage) and in methods of follow up (from self reported telephone surveys to intensive counselling with laboratory measures of alcohol related parameters). Accordingly rates of recidivism have varied greatly (from $9 \%-80 \%{ }^{17}$ ) with the majority of estimates being around $20 \%-30 \%$. Recidivism is considered undesirable because of recurrence of liver disease, decreased compliance with immunosuppression, ${ }^{18}$ and loss of support for transplantation programmes with the attendant loss of organ donations.

In contrast to "recidivism", recurrence of ALD has been defined as heavy drinking together with appropriate histological changes. ${ }^{19}$ There are very few studies of the incidence of recurrent ALD. Lee examined a series of 29 liver biopsies from patients with "excessive" postoperative alcohol consumption and abnormal liver function tests. ${ }^{19}$ Although $83 \%$ of biopsies showed steatosis, only $28 \%$ were fibrotic and a further $23 \%$ (six patients) had progressed to cirrhosis. Five of the patients with cirrhosis also had concurrent hepatitis $\mathrm{C}$ making it difficult to be sure whether the cirrhosis was due to alcohol. This study was also likely to over-estimate the frequency of recurrent ALD as no biopsies were taken from patients with recurrent drinking and normal liver function tests. However, combining these results with estimates of recidivism, the rate of recurrent fibrotic ALD after transplantation is probably less than $15 \%$, which is similar to other transplant indications.

The commonest method for limiting recurrence is use of the "six month rule" (that is requiring patients to be abstinent for six months before listing for transplantation). This rule is standard in the UK and many European transplant centres. ${ }^{17}$ The stated purpose of this rule is several fold. First, abstinence is said to be associated with decreased recidivism posttransplant. However, the evidence for this is limited. Bird et al examined the outcome of transplantation in 24 patients with ALD. ${ }^{20}$ All three patients who were drinking heavily before the transplant had laboratory evidence of recurrent alcohol abuse after transplant (although this was denied by all three patients, highlighting the difficulty in obtaining reliable estimates of recidivism). In comparison, only one of 21 long term abstinent patients returned to alcohol use. Kumar et al reported recidivism (identified though a telephone survey) among three of seven patients (43\%) abstinent for less than six months compared to three of 45 patients $(7 \%)$ abstinent for longer. ${ }^{21}$ In contrast, Pereira et al did not find any relationship between length of abstinence and rates of recidivism. ${ }^{22}$ The evidence that the six month rule promotes posttransplant abstinence is therefore slight. ${ }^{23}$

The second reason for advising at least six months of abstinence is to improve the immediate postoperative outcome. Evidence to support this is again limited. Only one study has reported reduced post-transplant survival in persistent drinkers (one year survival 68\% v 85\%). ${ }^{24}$ Furthermore, although alcoholic hepatitis at the time of transplantation is said to carry an extremely poor prognosis, the only study to examine the outcome of patients with alcoholic hepatitis on explant histology reported similar survival to patients with "pure" cirrhosis. ${ }^{25}$

The final (and probably most persuasive) argument for continuing to apply the six month rule is to give patients a chance to recover spontaneously and avoid transplantation. Many patients present to liver units with very advanced liver disease (as defined by either the Child-Pugh ${ }^{26}$ or Maddrey ${ }^{27}$ score) but will improve substantially with prolonged abstinence. The five year survival of patient with severe alcoholic cirrhosis (that is Child-Pugh stage C) with continued abstinence is over $50 \%,{ }^{28}$ which compares favourably with liver transplantation. Transplantation can then be considered for patients whose synthetic function has not improved after abstinence. Unfortunately, this approach does not guide the management of patients who continue to deteriorate to a life threatening degree within six months of ceasing to drink or who have a very occasional "slip" in this period.

Predicting which patients will return to excessive drinking is difficult. Recurrence is more likely where patients are truly alcohol dependent (as defined by DSM 4 or International Classification of Diseases, 10th revision), or have coexisting substance misuse, ${ }^{29}$ have had multiple previous failures at abstinence, ${ }^{30}$ have major psychiatric disorders (including depression), ${ }^{31}{ }^{32}$ or post-traumatic stress disorder. ${ }^{33}$ Finally lack of social support is associated with increased relapse. ${ }^{34}$

No single approach has been shown to prevent relapses. Both Weinrieb $^{23}$ and Beresford ${ }^{29}$ suggest that they can be minimised by continued supportive counselling and good relationships between staff and patients, supplemented by careful patient selection and treatment of associated psychiatric conditions.

In summary, ALD carries a similar prognosis to other liver diseases. Although the rate of recidivism is around 30\%, the risk of recurrent liver disease is probably much lower. The six 
month rule may be justified by allowing patients a chance to improve without transplantation, but evidence that it improves transplant outcome (whether medically or by minimising recidivism) is questionable.

TRANSPLANTATION AND RECURRENT HEPATITIS C

There are no overall population studies of the prevalence of hepatitis $\mathrm{C}$ in the UK. It affects $0.6 \%$ of blood donors ${ }^{35}$ and has been estimated to affect around $1 \%$ of the population. Infection frequency is much higher in other countries such as Italy (up to $3 \%$ ) ${ }^{36}$ and Egypt (up to $40 \%$ ). ${ }^{37}$ Altogether $75 \%$ of patients exposed to hepatitis $\mathrm{C}$ fail to clear the virus spontaneously and become chronically infected. After 20 years of chronic infection, approximately $20 \%$ of patients develop cirrhosis, whereafter there is a 3\% annual risk of hepatocellular carcinoma. Progression to cirrhosis is commoner with increasing length of infection, male sex, and alcohol use over $70 \mathrm{~g}$ ( seven units) per week. ${ }^{38}$ Although testing for hepatitis C has been possible for approximately 10 years, highly effective therapy with interferon and ribavirin has only been available for two years and interferon monotherapy (which is approximately half as effective) was only recommended in the UK in $2000 .^{39}$ Although in the future combination antiviral therapy may substantially reduce the number of patients with hepatitis C related cirrhosis and hepatocellular carcinoma, this is currently the commonest indication for liver transplantation in Europe and the USA. ${ }^{4}$

Hepatitis C imposes a large burden both on transplant services and hepatology services generally. As a proportion of patients cannot tolerate interferon related side effects and therapy is less effective in cirrhotic patients, ${ }^{41}{ }^{42}$ the majority of patients remain RNA positive (that is have active viral replication) at the time of transplantation. Although recurrence of peripheral viraemia and liver infection is virtually universal in RNA positive patients after transplantation (presumably from virus replicating in lymphocytes) ${ }^{43}{ }^{44}$ five year survival is similar to other accepted indications for transplantation. Hepatitis $\mathrm{C}$ is a well accepted indication for primary transplantation.

Recurrent hepatitis C may be defined as continued RNA positivity postoperatively together with histological changes consistent with viral liver damage. This affects up to $50 \%$ of grafts two years after transplantation. ${ }^{45}{ }^{46}$ Although rapidly progressive cholestatic hepatitis is described ${ }^{47}$ the majority of patients with histologically recurrent disease develop a slowly progressive chronic hepatitis. This follows an indolent course with only $6 \%$ of grafts being lost to recurrent disease after five years. ${ }^{48}$ Progression of graft hepatitis appears to be worse with certain hepatitis $\mathrm{C}$ genotypes (particularly $\mathrm{la}^{49}$ and $\mathrm{lb}^{48}$ ), increased immunosuppression (especially monoclonal antilymphocyte preparations and steroids), ${ }^{50}{ }^{51}$ and possibly certain donor HLA types. ${ }^{52}$ Of these only the immunosuppression regimen is amenable to clinical variation. Our unit currently treats hepatitis $\mathrm{C}$ transplant patients with tacrolimus monotherapy. Corticosteroids are used initially and rapidly weaned over one month. The choice of calcineurin inhibitor (for example cyclosporin or tacrolimus) does not appear to affect recurrence rates. ${ }^{53} 53$

Antiviral therapy after transplantation should theoretically reduce recurrent hepatitis. However, the immunostimulatory effects of interferon might also increase rejection episodes. Although there have been no controlled trials of interferon monotherapy, small series have not shown it to be beneficial. For example, Feray et al reported their experience with 14 patients. ${ }^{54}$ Four patients showed biochemical improvement but none achieved viral clearance and five suffered rejection. A preliminary report of a randomised controlled trial of interferon and ribavirin combination therapy suggests more success $(21 \%$ long term viral response with no increase in rejection). However, $41 \%$ of patients in this trial could not tolerate active treatment. ${ }^{55}$ The new immunosuppressant myco- phenylate mofetil prevents rejection through an azathioprinelike mechanism. However this agent can also inhibit inosine monphosphate dehydrogenase (the likely mechanism for ribavirin's effect). Preliminary reports suggest that patients treated with mycophenylate mofetil have lower hepatitis $\mathrm{C}$ virus RNA levels after transplantation although whether this translates into reduced histological recurrence is unclear. ${ }^{56}$

Although graft loss due to recurrent hepatitis only affects a small proportion of patients, the sheer number of transplants for hepatitis $\mathrm{C}$ means that absolute number of organs being lost is substantial. Retransplantation has a worse prognosis than initial transplantation and the rate and severity of recurrence of hepatitis in the second graft mirrors that in the first. ${ }^{51}$ The three year survival after retransplantation is only $54 \% .{ }^{51}{ }^{57}$ In the UK and the USA the feasibility of transplantation for recurrent hepatitis is seriously questioned given the donor: recipient mismatch.

\section{HEPATOCELLULAR CARCINOMA AND LIVER TRANSPLANTATION}

There are many theoretical attractions for treating hepatocellular carcinoma with liver transplantation. These include "complete removal" of malignant tissue, "cure" of the underlying liver disease (most hepatocellular carcinomas occur in cirrhotic livers), and removal of a diseased liver which has undergone "field change" predisposing it to further metachronous tumours. However the observed survival does not match these expectations due to tumour progression while waiting for transplantation, ${ }^{58}$ intraoperative micrometastasis, ${ }^{59}{ }^{60}$ and drug induced postoperative impairment of recipient tumour immunosurveillance. Three year survival rates after transplantation for hepatocellular carcinoma range from $18 \%$ to $69 \%,{ }^{61-64}$ and are the lowest of any indication for primary transplantation. Given this, there is increasing debate, particularly given current organ shortages whether patients with hepatocellular carcinoma should be treated with surgical resection or liver transplantation.

The "evidence base" gives little guidance to the optimum therapy. There are no randomised trials comparing transplantation and resection. Of six large series ${ }^{61-66}$ four have favoured transplantation and two resection. Interpretation of these series is hindered by selection bias between the therapy arms. Furthermore all six series excluded patients who were listed for transplantation but removed from waiting lists because of tumour progression. These "drop outs" have a poorer prognosis (two year survival 54\%) and account for up to $22 \%$ of referrals. Survival figures corrected for this (that is intention to treat survival) show little advantage of transplantation over resection..$^{58}$

As expected, transplantation works best in patients with small locally non-advanced tumours. However these are also exactly the patients who do best with resection or other locally curative therapy such as radiofrequency ablation. Current UK Transplant Special Support Authority guidelines suggest that transplantation should only be considered in patients with a $50 \%$ five year survival postoperatively. In practice this means that transplant may be considered for patients with three or less nodules of tumour all of which are less than $3 \mathrm{~cm}$ in diameter, or a single nodule less than $5 \mathrm{~cm}$ in diameter with no evidence of extrahepatic spread. The individual risks of resection versus transplantation may then be considered in patients fulfilling these criteria. Transplantation may be preferred in patients who are likely to do poorly with resection (due to advanced cirrhosis or portal hypertension ${ }^{58}$ ) or patients likely to have premalignant "field change" in the remaining liver segment (for example patients with viral cirrhosis or haemachromatosis). Conversely resection may offer a better chance of long term survival in patients with mild cirrhosis.

Preoperative assessment is vital when considering surgical options. Our unit currently assesses all patients with serum 
alpha fetoprotein, computed tomography of chest and abdomen, magnetic resonance imaging and angiography of abdomen, lipiodol angiography (combined with local chemotherapy (see below)), and laparoscopy.

Transcutaneous liver biopsy should not be used in the assessment of patients with hepatocellular carcinoma as this may disseminate localised potentially "curable" disease. Tumour seeding on the track of the biopsy has recently been reported in up to $5 \%$ of patients ${ }^{60}$ and tumour RNA may be detected peripherally in all biopsied patients. ${ }^{59}$ If the nature of a nodule is uncertain we currently perform biopsy at the time of assessment laparoscopy.

Resection rather than transplantation is generally the best option for the small group of patients with hepatocellular carcinoma developing in non-cirrhotic livers. A recent systematic review of 77 cases estimated that three and five year survival after transplant were just $29.8 \%$ and $11.2 \%{ }^{67}$

Fibrolamellar cancer is a rare primary liver tumour. It tends to affect younger patients than hepatocellular carcinoma and to develop de novo in non-cirrhotic livers. Furthermore it is slow growing and patients may have reasonable long term survival even following recurrence. The largest series of patients with fibrolamellar carcinoma reported $70 \% 10$ year survival with resection and $28 \%$ with transplantation. ${ }^{68}$ Although better survival after transplantation has been reported in other series (for example 55\% five year survival ${ }^{69}$ ), resection probably remains the most effective treatment for fibrolamellar tumours.

Chemotherapy may improve survival and minimise tumour progression in patients with hepatocellular carcinoma waiting for transplantation. Although, again there are no randomised controlled trials of this therapy, comparison to historical controls does seem to suggest a benefit. This seems particularly effective when given locally by transarterial chemoembolisation where five year survival rates of up to $79 \%$ have been reported.$^{68-70}$ The roles of intraoperative and postoperative chemotherapy are less clear.

As waiting times substantially affect the success of transplantation, ${ }^{58}$ hepatocellular carcinoma may be a suitable indication for living related resection and donation. However, as above, this technique is not widely available in the UK and donors are only available for $15 \%$ of patients. ${ }^{71}$

\section{REFERRAL FOR TRANSPLANTATION}

The American Medical Association Committee on Ethical Issues has outlined acceptable and unacceptable criteria for selection for liver transplantation (see box 1). ${ }^{72}$ Neuberger and James, in association with a large committee of stakeholders (including lay members and patient representatives), supplemented these criteria in the UK. ${ }^{73}$ Neuberger and James outlined four fundamental concepts based "on the fact that the liver resource is limited rather than cost benefit [considerations]". First, local and national guidelines for transplantation should be agreed by all stakeholders including patient representatives. Second, patients should primarily be selected on the basis of poor quality of life and/or anticipated very limited life expectancy without transplantation (usually less than one year), thus restricting transplantation to the severest cases of liver disease. Third, patients should not be offered transplantation if there is a less than $50 \%$ expected survival five years after surgery, thus limiting transplant to patients with maximum potential for benefit. Finally, livers should be allocated to maximise outcome "in preference to allowing every possible recipient to have a chance of an organ". These concepts emphasise the importance of choosing patients to maximise benefit rather than merely on severity of patient illness.

As the majority of hepatologists and gastroenterologists in the UK do not work in liver transplant units, most patients
Box 1: American Medical Association ethical criteria for liver transplantation

Acceptable criteria

- Likelihood of benefit for the patient

- Importance of the treatment in improving patient quality of life.

- Duration of anticipated benefit.

- Urgency of treatment.

- Likely amount of resources required.

Unacceptable criteria

- Patient's (or insurer's) ability to pay.

- Contribution of patient to society.

- Perceived obstacle to treatment (for example, antisocial personality, alcohol abuse, transport difficulties).

- Patient's contribution to their medical condition (for example, alcohol consumption or drug abuse).

- Previous use of medical resources.

will be referred to tertiary centres when considered for transplantation. As local policies differ between units, all inclusive national referral guidelines are not possible and potential cases should be discussed with local units and treated according to local protocols.

Patients should ideally be referred at a time when irreversible progressive impairment of liver function is apparent but not so advanced to increase the risks of transplantation. Progressive immune disorders such as primary sclerosing cholangitis, primary biliary cirrhosis, autoimmune hepatitis, or chronic metabolic disorders (such as haemachromatosis of antitrypsin deficiency) or viral hepatitis should be referred relatively early when irreversible hepatic synthetic impairment or problematic portal hypertension have developed. Advanced prognostic models in primary biliary cirrhosis and primary sclerosing cholangitis may augment referral decisions. As active viral replication substantially reduces posttransplant survival, it may be appropriate to institute antiviral therapy before transplantation in patients with hepatitis B.

Patients may also be considered for transplantation when symptoms significantly impair quality of life (for example intractable pruritus or fatigue in cholestatic liver disease).

Patients with potentially curable hepatocellular carcinoma should be referred for consideration as early as possible. This both maximises the chance of successful transplantation and potentially allows other surgical or locally active therapy to be considered in patients not suitable for transplantation. Patients with suspected hepatocellular carcinoma should not undergo percutaneous liver biopsy before referral.

ALD presents the greatest challenge for referral. Patients should either be abstinent or have a reasonable chance of abstinence at the time of referral for transplantation. Although some units will accept patients who are actively drinking for specialist conservative medical therapy, most would be unlikely to accept these patients for consideration of transplantation because of reduced chance of benefit from surgery.

Absolute contraindications to transplantation include extrahepatic infection (including HIV), advanced malignancy, or poor cardiovascular/respiratory status. Patients with serious psychiatric illness may not be suitable for transplantation. There is no absolute age cut off for transplantation but comorbidity and reduced expected postoperative survival mean that relatively few transplants are performed in patients aged over 65 years.

Liver transplantation has radically changed the prognosis for patients with progressive liver failure or impaired quality of life due to liver disease. Future challenges and advances may reduce the mismatch between need for transplantation and supply of organs. 


\section{ACKNOWLEDGEMENTS}

The authors thank Mr Derek Manas for his editorial advice on this manuscript

\section{Authors' affiliations}

M I Prince, M Hudson, Freeman Hospital Liver Unit, Freeman Hospital, Newcastle upon Tyne, UK

\section{REFERENCES}

1 Starzl TE, Groth CG, Brettschneider L, et al. Orthotopic

homotransplantation of the human liver. Ann Surg 1968;168:392-415.

2 Bravat DM, Olkin I, Barnata AE, et al. Health related quality of life after liver transplantation: a meta-analysis. Liver Transplantation and Surgery $1999 \cdot 5 \cdot 318-31$

3 Totsuka E, Fung JJ, Urakami A. Influence of donor cardiopulmonary arrest in human liver transplantation: possible role of ischemic preconditioning. Hepatology 2000;31:577-80.

4 Urena MA, Moreno Gonzalez E, Romero CJ, et al. An approach to the rational use of steatotic donor livers in liver transplantation. Hepatogastroenterology 1999;46:1 164-73.

5 Shah G, Demetris AJ, Irish W, et al. Frequency and severity of HCV infection following orthotopic liver transplantation. Effect of donor and recipient serology for $\mathrm{HCV}$ using a second generation ELISA test. J Hepatol 1993; 18:279-83.

6 Vargus HE, Laskus T, Wang L-F, et al. Outcome of liver transplantation in hepatitis $C$ virus infected patients who received hepatitis $C$ infected grafts. Gastroenterology 1999;177:149-55.

7 Bustil R, Goss J. Split liver transplantation. Ann Surg 1999;229:311221.

8 Reyes J, Gerber D, Mazariegos G, et al. Split liver transplantation: a comparison of ex situ and in vivo techniques. J Pediatric Surg 2000;35:283-9

9 Marcos A. Split liver transplantation for adult recipients. Liver Transplantation 2000;6:707-9.

10 Todo S, Furukawa $\mathrm{H}$, Jin MB, et al. Living donor liver transplantation in adults: outcome in Japan. Liver Transplantation 2000;6(suppl 2):S66-72.

11 Marcos A. Right lobe living donor transplantation. Liver Transplantation 2000;6(suppl 2):S59-63.

12 Kiuchi T, Kasahara M, Uryuhara $H$, et al. Impact of graft size mismatching on graft prognosis in liver transplantation from living donors. Transplantation 1999;27:321-7.

13 Shapiro RS, Adams M. Ethical issues surrounding adult to adult dono liver transplantation. Liver Transplantation 2000;6(suppl 2):S77-80.

14 Miwa S, Hishakura Y, Mita A, et al. Living related transplantation for patients with fulminant or sub-fulminant liver failure. Hepatology 1999;30:1521-6.

15 Neuberger J, Adams D, Macmaster P, et al. Assessing priorities for allocation of donor liver grafts: survey of public and clinicians. BM 1998;317:172-5.

16 Belle SH, Beringer KC, Detre KM. Liver transplantation for alcoholic live disease in the United States: 1988 to 1995. Liver Transplantation and Surgery 1997;3:212-19.

17 Neuberger J, Tang H. Relapse after transplantation: European studies. Liver Transplantation and Surgery 1997;3:275-9.

18 Campbell DA, Magee JC, Punch JD, et al. One centre's experience with liver transplantation: alcohol relapse over the long term. Liver Transplantation and Surgery 1998;4:S58-64.

19 Lee RG. Recurrence of alcoholic liver disease after transplantation. Liver Transplantation and Surgery 1997;3:292-5.

20 Bird GL, O'Grady JG, Harvey FA, et al. Liver transplantation in patients with alcoholic cirrhosis: selection criteria and rates of survival and relapse. BM/ 1990:301:15-17.

21 Kumar S, Stauber RE, Gavaler J, et al. Orthotopic liver transplantation for alcoholic liver disease. Hepatology 1990;1 1:159-64.

22 Pereira SP, Howard LM, Rela M, et al. Quality of life after transplantation for alcoholic liver disease. Liver Transplantation 2000;6:762-8

23 Weinrieb RM, Van Horn DHA, McLellan AT, et al. Interpreting the significance of drinking by alcohol dependent liver transplant patients: fostering candour is the key to recovery. Liver Transplantation 2000;6:769-76

24 Weissner RH, Lombardero M, Lake JR, et al. Liver transplantation for end stage alcoholic disease: an assessment of outcomes. Liver Transplantation and Surgery 1997;3:321-9.

25 Shakil AO, Pinna A, Demetris J, et al. Survival and quality of life after liver transplantation for acute alcoholic hepatitis. Liver Transplantation and Surgery 1997;3:240-4

26 Child CG, Turcotte JG. The liver and portal hypertension. Philadelphia: Saunders, 1964: 49-50.

27 Maddrey WC, Boitnott JK, Bedine MS, et al. Corticosteroid therapy of alcoholic hepatitis Gastroenterology 1978;75:193-9.

28 Powell WJ Jr, Klatskin G. Duration of survival in patients with Laennec's cirrhosis. Influence of alcohol withdrawal and possible effects of recent changes in general management of the disease. Am J Med 1968;44:406-20.

29 Beresford TP. Predictive factors for alcoholic relapse in the selection of alcohol dependent persons for hepatic transplant. Liver Transplantation and Surgery 1997;3:280-91
30 Gish RG, Lee AH, Keefe EB, et al. Liver transplantation for patients with alcoholism and end stage liver disease. Am J Gastroentero 1993;88:1337-42.

31 Merikangas KR, Glernter CS. Comorbidity for alcoholism and depression. Psychiatr Clin North Am 1990;13:613-32.

32 Grant BF, Harford TC. Comorbidity between DSM IV alcohol use disorders and major depression: results of a national survey. Drug Alcohol Depend 1995;39:197-206.

33 Fireman M. Prediction of substance abuse relapse following liver transplant. Forth conference on psychiatric, psychosocial and ethical issues in organ transplantation. San Antonio, Texas, 1996.

34 Strauss R, Bacon SD. Alcoholism and social stability, a study of occupational integration of 2023 male clinic patients. Quarterly Journal of Studies in Alcoholism 1951;12:231-60.

35 Garson JA, Clewley JP, Simmonds P, et al. Hepatitis C viraemia in United Kingdom blood donors. A multicentre study. Vox Sang 1992:62:218-23.

36 Baldo V, Floreani A, Menegon T, et al. Hepatitis C virus, hepatitis B virus and human immunodeficiency virus infection in pregnant women in north-east Italy: a seroepidemiological study. Eur J Epidemiol 2000;16:87-91.

37 Frank C, Mohamed MK, Strickland GT, et al. The role of parenteral antischistosomal therapy in the spread of hepatitis $C$ virus in Egypt. Lancet 2000;355:887-91

38 Degos F. Hepatitis C and alcohol. J Hepatol 1999;31(suppl 1):113-18.

39 National Institute for Clinical Excellence. Guidance on the use of ribavarin and interferon alpha for hepatitis C. NICE technology appraisal guidance No 14. London: NICE, October 2000 (www.nice.org.uk).

40 US Department and Health and Human Service. Annual report of the US scientific registry for organ transplantation and the organ procurement and transplantation network-transplant data 1988-1998. Richmond VA: UNOS and Rockville, MD: US Department and Health and Human Service, 1998.

41 Bizollon T, Ducerf C, Trepo C, et al. Hepatitis $C$ virus recurrence after liver transplantation. Gut 1999;44:575-8

42 Poynard T, Marcellin P, Lee SS, et al. Randomised trial of interferon $2 b$ plus ribavirin for 48 weeks or for 24 weeks versus interferon $2 \mathrm{~b}$ plus placebo for 48 weeks for treatment of chronic infection with hepatitis $C$ virus. Lancet 1999;352:1426-50.

43 Wright TL, Donnegan E, Hsu HH, et al. Recurrent and acquired hepatitis $\mathrm{C}$ infection in liver transplant recipients. Gastroenterology 1992; 103:317-22

44 Chazoulieres O,Kim M, Combes C, et al. Quantification of hepatitis C virus in liver transplant recipients. Gastroenterology 1994;106:994-9.

45 Ferrel L, Wright TL, Roberts J. Hepatitis C infection in liver transplant recipients. Hepatology 1992;16:865-76.

46 Loinaz C, Lumbreras C, Gonzales Pinto L, et al. High incidence of post-transplant hepatitis and chronic rejection associated with hepatitic $C$ virus infection in liver transplant recipients. Transplant Proc 1995; 27:1217-18.

47 Read AE, Donegan E, Lake $K$, et al. Hepatitis $C$ in patients undergoing liver transplantation. Ann Intern Med 1991;114:282-4.

48 Gane EJ, Portman EC, Naumov NV, et al. Long term outcome of hepatitis C after liver transplantation. N Engl J Med 1996:334:815-20.

49 Scheiner EA, Schluger LK, Emre S, et al. Severe recurrent cholestatic hepatitis $C$ following liver transplantation. Liver Transplantation and Surgery 1997; 3:130-6

50 Berenguer $M$, Watson J, Crippin J, et al. A model to predict hepatitis $C$ related fibrosis progression following liver transplantation. Hepatology 200;32 (4 part 2):217A

51 Testa G, Crippin JS, Notto GJ, et al. Liver transplantation for hepatitis C: recurrence and disease progression in 300 patients. Liver Transplantation 2000;6:553-61

52 Gretch G, Wile M, Gaur L, et al. Donor recipient match at the HLA-DQ8 locus is associated with recrudescence of chronic hepatitis $C$ after transplantation. Hepatology 1993;18(suppl): 18A.

53 Martin P, Crippin J, Goldstein RM, et al. Primary immunosuppression agent does not affect hepatitis $C$ recurrence rates after liver transplantation. Hepatology 2000;32(4 part 2):259A.

54 Feray C, Samuel D, Gigou M, et al. An open trial of IFN alpha for hepatitis $C$ after liver transplantation: antiviral effects and risk of rejection. Hepatology 1995;22:1084-9

55 De Vera ME, Smallwood GA, Davis L, et al. Interferon A and ribavirin for the treatment of recurrent hepatitis $C$ after liver transplantation. Hepatology 2000;32 (4 part 2):290A.

56 Ardesch J, Sreekumar R, Burgart $\mathrm{L}$, et al. Hepatitis $C$ recurrence after liver transplantation: the impact of mycophenylate mofetil. Hepatology 2000;32(4 part 2):258A.

57 Kim WR, Charlton $M$, Weissner RH, et al. Patient and graft survival following hepatic retransplantation in patients with hepatitis $C$. Hepatology 2000;32(4 part 2):257A.

58 Llovett JM, Fuster J, Bruix J. Intention to treat analysis of surgica treatment for hepatocellular carcinoma: resection versus transplantation. Hepatology 1999;30:1434-40.

59 Louha M, Nicolet J, Zylberberg H, et al. Liver resection and needle biopsy cause haematogenous dissemination of liver cell cells. Hepatology 1999;29:879-82.

60 TakamoriR, Wong II, Damg C, et al. Needle-tract implantation from hepatocellular carcinoma: is needle biopsy of the liver always necessary? Liver Transplantation 2000;6:67-72.

61 Ringe B, Pichlmayr R, Witlekind C, et al. Surgical treatment of hepatocellular carcinoma. Experience with liver resection and transplantation in 98 patients. World J Surg 1991;15:270-85. 
62 Iwatsuki S, Strazl T, Sheahan DG, et al. Hepatic resection versus transplantation for hepatocellular carcinoma. Ann Surg 1991;214:221-9.

63 Bismuth H, Chiche L, Adam R, et al. Liver resection versus transplantation for hepatocellular carcinoma in cirrhotic patients. Ann Surg 1993;218:141-5.

64 Tan KC, Rela M, Ryder SD, et al. Experience of orthotopic liver transplantation and hepatic resection for hepatocellular carcinoma less than 8cm in patients with cirrhosis. Br J Surg 1995;82:253-6.

65 Otto G, Heuschen U, Hoffmann WJ, et al. Survival and recurrence after liver transplantation versus resection for hepatocellular carcinoma. Ann Surg 1998;227:424-32.

66 Michel J, Suc B, Fourtanier G, et al. Recurrence of hepatocellular carcinoma after resection or transplantation. Tranplant Proc 1995:27:1977-801.

67 Houben KW, McCall JL. Liver transplantation for hepatocellular carcinoma in patients without underlying liver disease: a systematic review. Liver Transplantation and Surgery 1999;5:91-5.
68 Pinna AD, Iwatsuki S, Leee RG, et al. Treatment of fibrolamellar carcinoma with subtotal hepatectomy or transplantation. Hepatology 1997;26:877-83

69 Llovett JM, Bruix J, Fuster J, et al. Liver transplantation for small hepatocellular carcinoma. The TNM classification does not have prognostic power. Hepatology 1998;27:1572-7.

70 Figueras J, Juarieta $\mathrm{E}$, Valls $\mathrm{C}$. Survival after liver transplantation: a comparative study. Hepatology 1997;25: 1485-90.

71 Trotter JF, Wachs M. Evaluation of 100 patients for living donor liver transplantation. Liver Transplantation 2000;6:290-5.

72 Council on Ethical and Judicial Affairs, American Medical Association. Ethical demand for liver transplantation. Clin Transpl 1997;11:49-55

73 Neuberger J, James $\bigcirc$. Guidelines for selection of patients for liver transplantation in the era of donor-organ shortage. Lancet 1999;354:1636-9

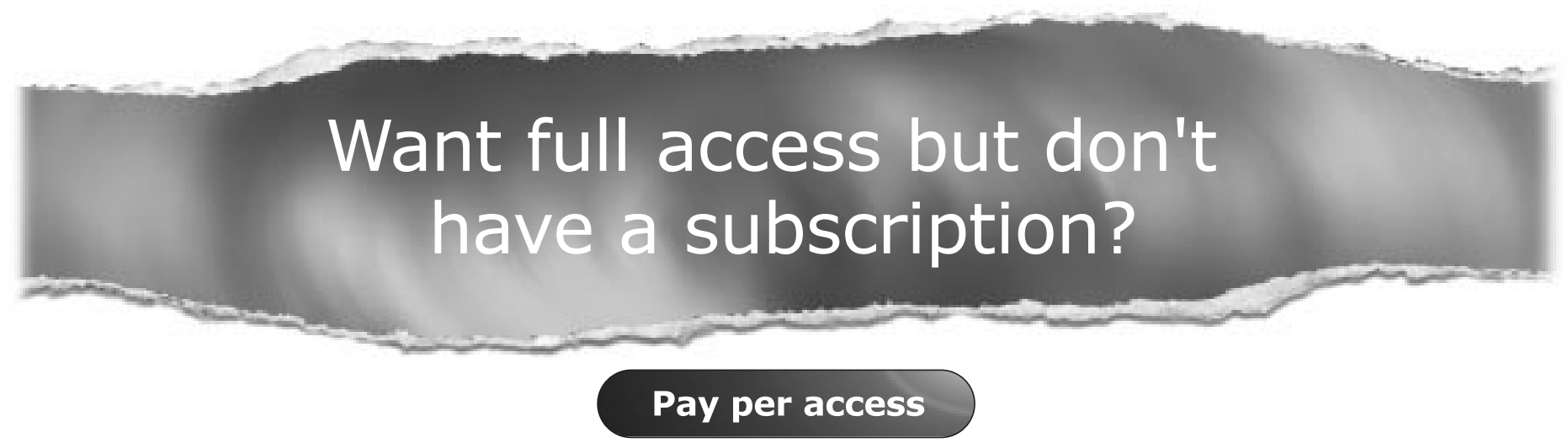

For just US\$25 you can have instant access to the whole website for 30 days. During this time you will be able to access the full text for all issues (including supplements) available. You will also be able to download and print any relevant pdf files for personal use, and take advantage of all the special features Postgraduate Medical Journal online has to offer.

\section{www.postgradmedj.com}

